\title{
Synthesis and Photophysical Properties of Fluorescent 6-Aryl-D- $\pi$-A Coumarin Derivatives
}

\author{
Andrea Cocco, Paola Caria, Giuseppina Sanna, Luigi Stagi, Enzo Cadoni, Riccardo Corpino, \\ Pier Carlo Ricci, Carlo Maria Carbonaro,* and Francesco Secci*
}

Cite This: ACS Omega 2021, 6, 33708-33716

Read Online

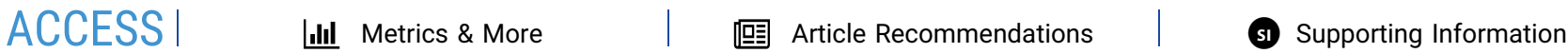

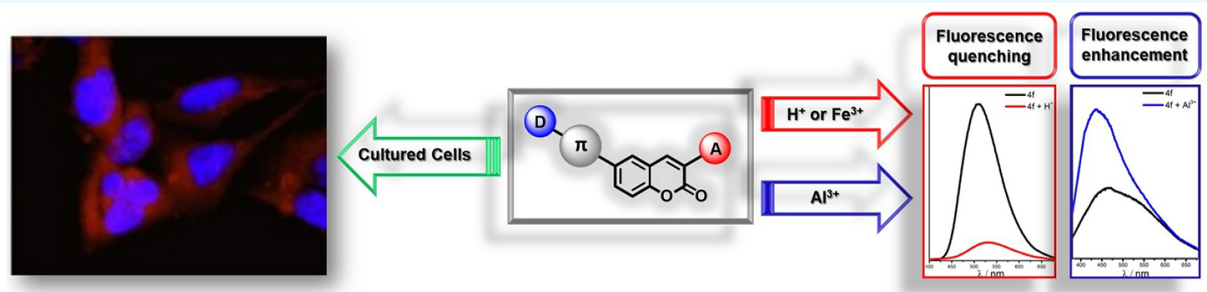

ABSTRACT: A series of 6-aryl coumarin dyes were synthesized in satisfactory yields by Pd-catalyzed Suzuki cross-coupling reactions with a panel of boronic acids and coumarin bromides. Photophysical studies highlighted a large Stoke shift and interesting fluorescence quantum yield for these compounds. Optical properties were also investigated with the aid of quantum chemical calculations. The treatment of selected coumarin dyes with increasing amounts of trifluoroacetic acid showed that their fluorescence can be strongly influenced by $\mathrm{pH}$ (fluorescence quenching at high acid concentrations), while the addition of $\mathrm{Fe}^{3+}$ and $\mathrm{Al}^{3+}$ metal ions allowed to highlight dichotomous behavior with the corresponding reduction in fluorescence with the increase of $\left[\mathrm{Fe}^{3+}\right]$ or $\left[\mathrm{Al}^{3+}\right]$. Finally, biological assays and fluorescence microscopy imaging investigations indicated that these compounds can be used as potential biomarkers in living and fixed cells.

\section{INTRODUCTION}

Coumarin derivatives represent an important class of heterocyclic compounds possessing many significant electrooptical properties as well as showing different biological activities. $^{1-5}$ These molecular scaffolds are generally characterized by high fluorescence, large Stokes shifts, high photoluminescence quantum yield (PLQY), sensitivity, dual emission, internal charge transfer (ICT), and twisted ICT properties. ${ }^{6,7}$ For all of these reasons, coumarin adducts find application in various research fields such as laser dyes, ${ }^{8}$ organic light-emitting diode fabrication, ${ }^{9}$ and dye-sensitized solar cells ${ }^{10}$ as cell-imaging biomarkers ${ }^{11}$ or optical brighteners. ${ }^{12}$ The visible absorption properties of such compounds are highly controlled by the insertion of various substituents directly bonded to the heteroaromatic structure, and in particular, coumarin functionalization by the insertion of electron-donating groups (EDGs) in the positions C5 or C7 and electron-withdrawing groups (EWGs) in the positions $\mathrm{C} 3$ or $\mathrm{C} 4$ has been previously investigated. ${ }^{13}$ By analyzing several coumarin derivatives used in dye laser applications, Zeidler and co-workers observed that the benzene rings of these compounds showed a predominant para-quinoidal resonance state, determined by a "push-pull" effect, which leads to intramolecular charge transfer (ICT) with consequent shortening of the C5-C6 and C8-C9 bonds. The increase in the "push-pull" effect ${ }^{14 a-c}$ reduces the coumarin band gaps leading to a spectral redshift in UV-vis absorption. The increase in the redshift and molar extinction coefficients could also be obtained by selectively inserting an EWG in the C3 position. ${ }^{14 \mathrm{c}}$ Moreover, Imai and co-workers, highlighted how high PLQY values could be achieved by using C6 or C7 EDG functionalized coumarins. ${ }^{15}$

Finally, $\pi$-expanded coumarin derivatives, ${ }^{16}$ such as benzocoumarins or vertically $\pi$-expanded derivatives, revealed redshifted absorption and emission and improved quantum fluorescence yields compared to the simple bicyclic compounds (Figure 1). ${ }^{17}$ These achievements and the continuous investigations in this field indicate that the rational synthesis of donor- $\pi$-acceptor (D- $\pi$-A) fluorescent molecules is still of fundamental importance because of their centrality in material science. Herein, we report a rational study concerning the synthesis and the photophysical characterization of new coumarin structures containing various aromatic spacers between the heteroaromatic coumarin scaffold and the EDG, aimed to increase the push-pull system conjugation and to

Received: September 1, 2021

Accepted: November 10, 2021

Published: November 30, 2021 
<smiles>COC(=O)c1cc2cc3ccc(O)cc3cc2oc1=O</smiles>

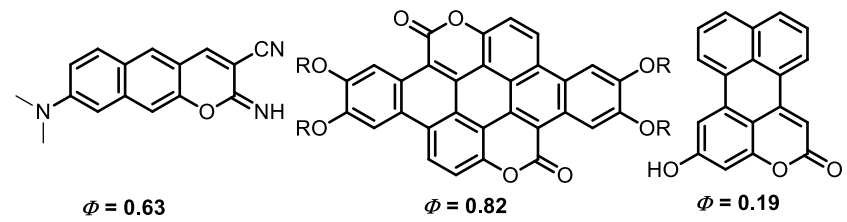<smiles></smiles>
$\Phi=\mathbf{0 . 8 2}$

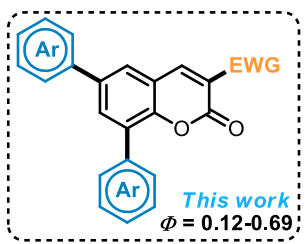

Figure 1. Representative push-pull fluorescent coumarin systems.

select new candidate molecules for the construction of performing nontoxic biomarker dyes with efficient emissions in the blue-green spectral region.

\section{RESULTS AND DISCUSSION}

2.1. Synthesis and Theoretical Calculations. 6-Aryl coumarins were synthesized from 1a by a simple two-step procedure consisting of Knoevenagel condensation (with diethyl malonate or malononitrile $)^{21}$ yielding the bromo derivatives $3 a-3 c{ }^{21 c-e}$ followed by $\operatorname{Pd}(0)$-catalyzed Suzuki cross-coupling reaction with selected boronic acids, affording the corresponding adducts $\mathbf{4 a - 4} \mathbf{f}$ in satisfactory yields. Following the same strategy, 6,8-diaryl-coumarins $\mathbf{5 a - 5 b}$ and $\mathbf{5 d}$ were prepared from the aldehyde $\mathbf{1 b}$ as summarized in Scheme 1. Then, quantum chemical calculations were performed in order to predict the electronic properties of these compounds. From this investigation, we observed that 6aryl coumarins do not assume a planar geometry as expected because the EWGs tend to rotate with respect to the coumarin plane.

Also, the analysis of the atomic distances and angles indicated that in the excited state, all the studied derivatives have shown a more planar structure than in the ground state, as a consequence of the redistribution of the electric charge. As shown in Figure 2, we report the calculated HOMO and LUMO for compound $4 a^{21 e}$ as an illustrative example (details of the other coumarins $\mathbf{4}$ and $\mathbf{5}$ can be found in the Supporting Information).

The dihedral angle between the coumarin plane and the EDG (donor group) changes by about $11 \%$ in the excited state as compared to the ground state, while the electronic charge changes mainly on the carbon atoms of the coumarin rings, with the largest decrease of negative charge recorded in the C3 position, which is the one bridging the EWG acceptor group (COOEt for 4a). Similar results were observed for all the synthesized coumarins, with a variation of the dihedral angle in the 5-11\% range, where the lowest variation was recorded for 4 c. In the case of disubstituted coumarins bearing two EDGs in the $\mathrm{C} 6$ and $\mathrm{C} 8$ positions (Scheme 1, compounds $\mathbf{5 a}, \mathbf{5 b}$, and 5d), both substituents undergo similar variation in the excited state as compared to the ground state, leading to a more planar structure. These data are confirmed by the molecular orbital (MO) calculations shown in Figure 2 (and Supporting
Scheme 1. Synthetic Route to 6- and 6,8-Aryl Coumarin Derivatives
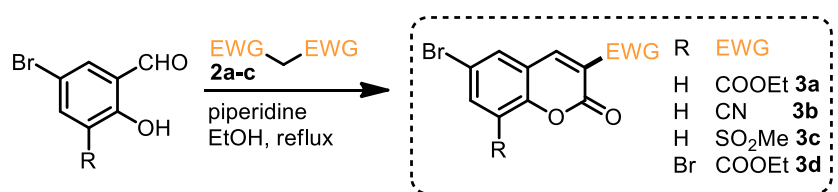

$\mathrm{R}=\mathrm{H} \quad 1 \mathrm{a}$

$\mathrm{R}=\mathrm{Br} 1 \mathrm{~b}$
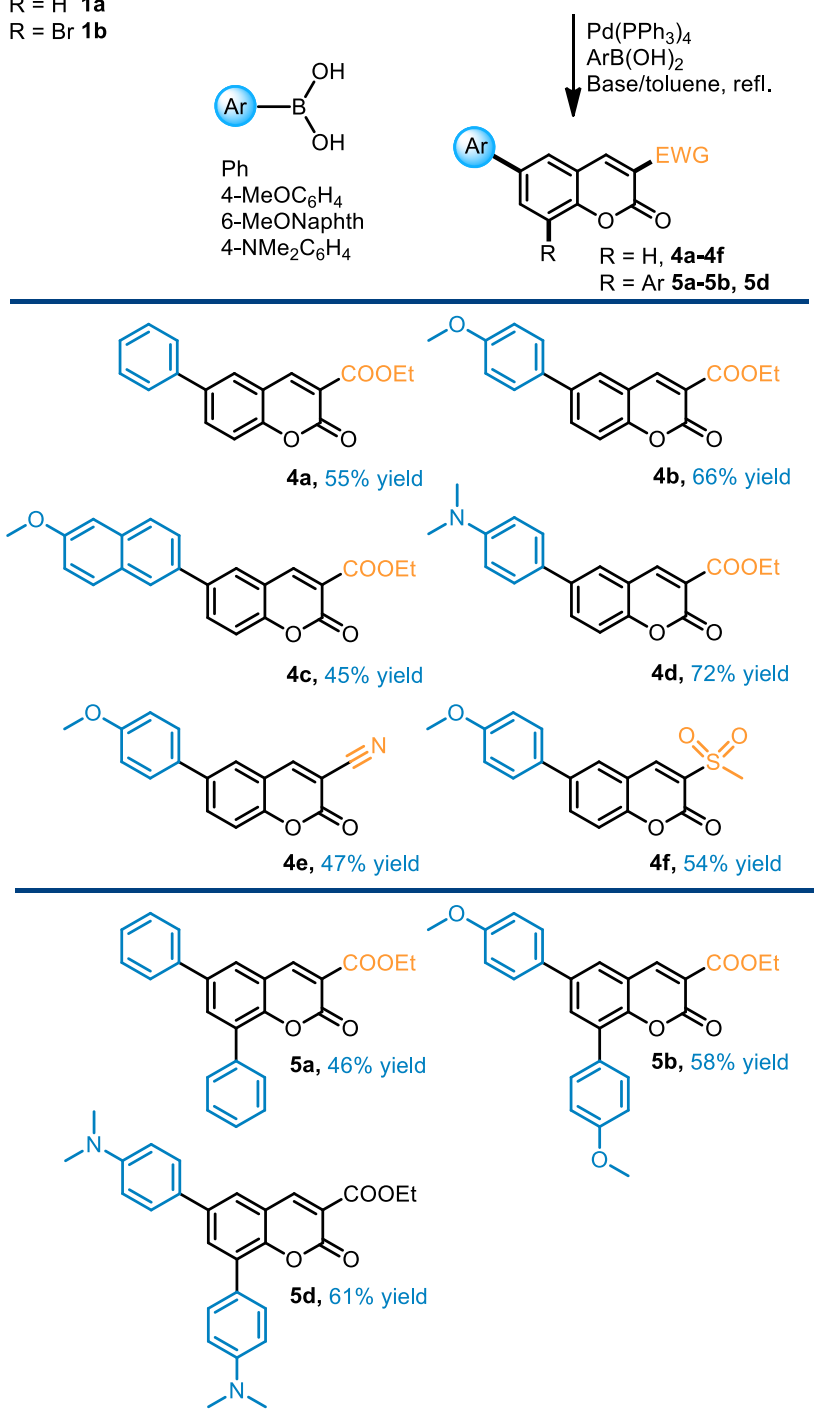

$\mathbf{4 b}, 66 \%$ yield

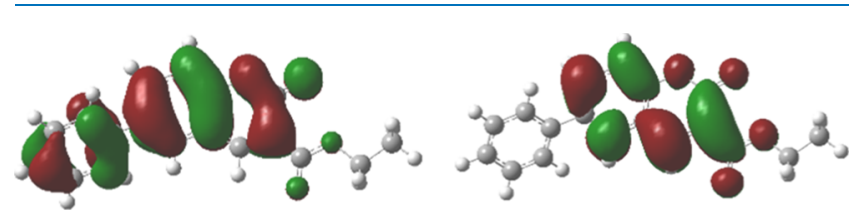

Figure 2. Ball and stick representation of the 4a derivative $(\mathrm{H}=$ white, $\mathrm{O}=$ red, and $\mathrm{C}=$ gray). HOMO and LUMO (left and right, respectively) represent the charge distribution (isocontour value $=$ $0.02 \mathrm{au})$.

Information) for the HOMO and LUMO. Upon excitation, these molecules undergo structural and electronic reorganization, leading to an electron density pinned on the coumarin plane and partially to the acceptor group, with no contribution from the donating ones. However, a complete charge transfer to the acceptor group is observed only for compound $\mathbf{4 d}$. The TDDFT calculations allowed also us to estimate the absorption 

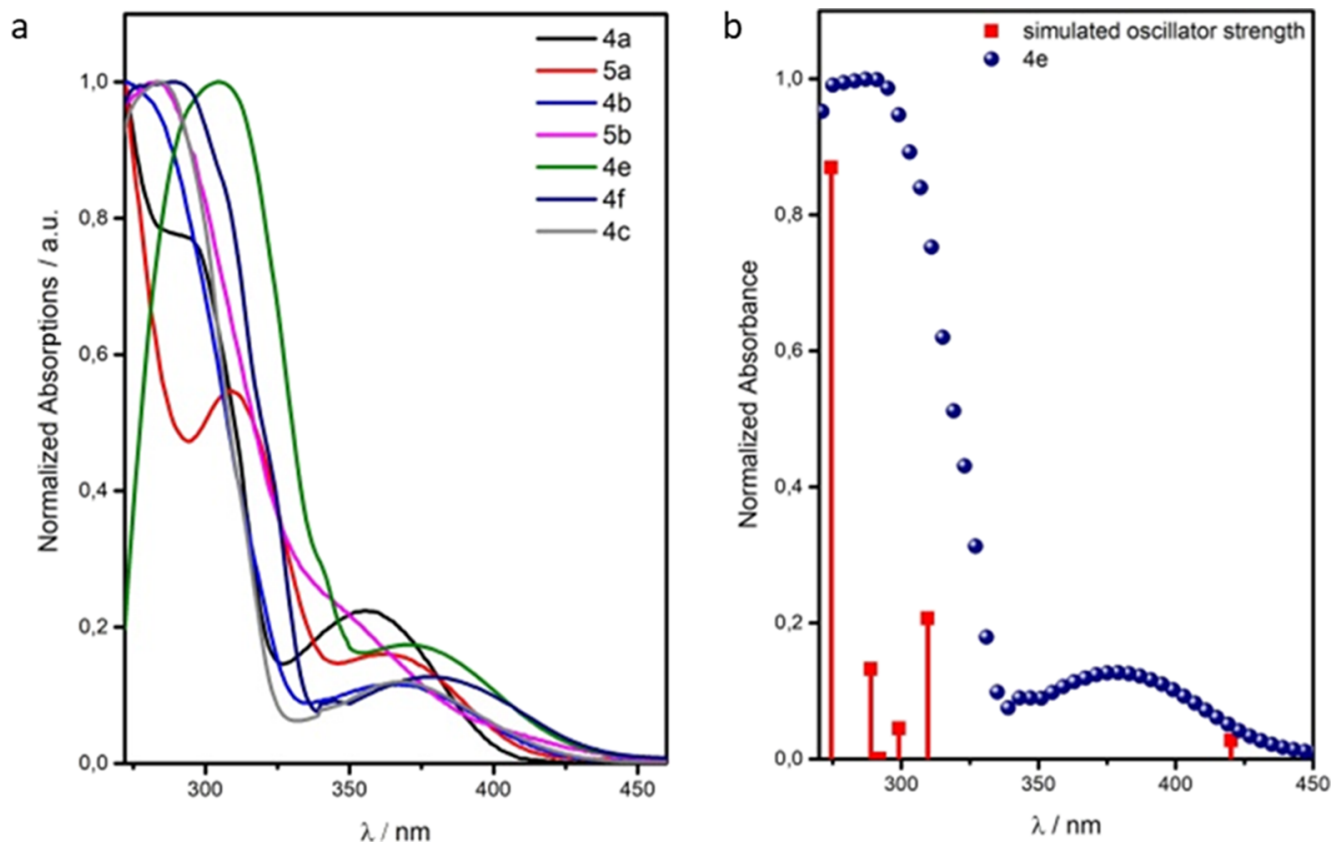

Figure 3. (a) Absorbance spectra of investigated coumarins. (b) Absorbance spectrum and simulated oscillator strength of the 4e sample in chloroform.
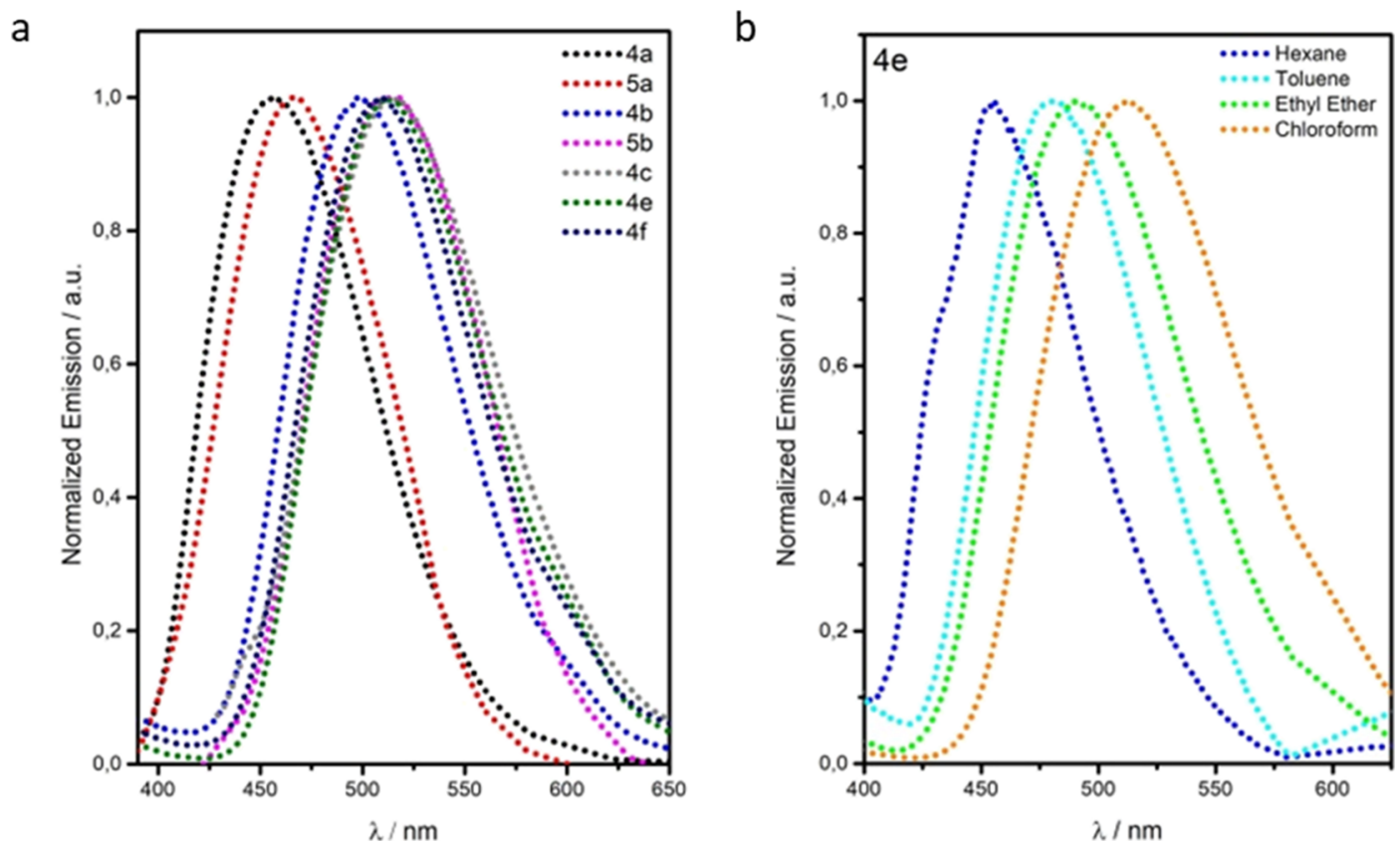

Figure 4. (a) PL spectra of investigated coumarins in chloroform excited at $340 \mathrm{~nm}$. (b) PL spectra of the 4e sample in different solvents excited at $300 \mathrm{~nm}$.

and emission features of these compounds, which are schematically shown in Figure 3 (vacuum, see Supporting Information, Table S1 for details). The HOMO-LUMO transitions have been calculated at $420 \mathrm{~nm}$, and the related emission was obtained at $512 \mathrm{~nm}$. When the model solvent is considered, a redshift is reported for both absorption and emission features, leading to 442 and $549 \mathrm{~nm}$, respectively, with similar structural and electronic properties in terms of spatial orientation and MOs. The simulated optical properties indicate that the substitution of the benzene fused ring with EDGs with increasing donating character, from phenyl (4a) to para methoxy-phenyl (4b) $)^{21 \mathrm{e}}$ and 6-methoxy-naphthyl (4c) groups, lead to an estimated absorption wavelength increase, and consequently, an increase of the emissions of about $75 \mathrm{~nm}$, moving the HOMO-LUMO transition from the near UV (362 $\mathrm{nm}$ for $4 \mathrm{a})$ to the blue spectral region (435 $\mathrm{nm}$ for $4 \mathrm{c}$ ) and the emission from blue (444 $\mathrm{nm}$ for $4 \mathrm{a})$ to green $(532 \mathrm{~nm}$ for $4 \mathrm{c}$ ). Moreover, the variation of the acceptor group, from ethyl ester $(\mathbf{4 b})$ to nitrile $(\mathbf{4 e})$ or sulfone $(\mathbf{4 f})$ groups, shows a redshift of about $20 \mathrm{~nm}$ for $4 \mathrm{a}$, while no significant differences were observed for the compounds $4 \mathrm{~b}$ and $4 \mathrm{e}$. However, C6 and C8 diaryl-disubstituted coumarins, such as $\mathbf{5 a}$ and $\mathbf{5 b}$, show an absorption redshift of about $20 \mathrm{~nm}$ and emission of 40 $\mathrm{nm}$, in comparison to the C6 monosubstituted derivatives. 
Finally, as already stated before, for all the simulated coumarins, the presence of solvent causes an almost rigid redshift for the calculated optical properties.

2.2. Optical Characterization of Aryl Coumarins 4 and 5. Figure $3 \mathrm{a}$ shows a comparison of the experimental absorption spectra of coumarins $4 a-4 c, 4 f$, and $5 a-5 b$. All the spectra show two main excitations; the first one in the far UV around $300 \mathrm{~nm}$ and the second one in the $300-400 \mathrm{~nm}$ region. As depicted, the largest redshift is observed for $\mathbf{4 e}$, in good agreement with the simulated results (Figure $3 \mathrm{~b}$ ). A detailed comparison of the coumarin absorption spectra as a function of the substitution is reported in the Supporting Information.

Absorption analyses conducted with compounds 4a (6phenyl), 4b [6-(4-methoxyphenyl)], and 4c [6-(6-methoxynaphthyl)] were in good agreement with these simulations (Figure 3b). Keeping the 6-(4-methoxyphenyl) unit and varying the acceptor group at the $\mathrm{C} 3$ position from the ethyl ester moiety (4b) to nitrile (4e) gave superposable trends with the calculated spectra. On the other hand, the absorption spectra of compound $4 \mathrm{~d}$, bearing 6-(4-N,N-dimethylphenyl) as a donor group and a carboxyethyl function as acceptor, showed a redshift of about $20 \mathrm{~nm}$ to respect the predicted ones. On the contrary, predictions regarding the photophysical properties of disubstituted coumarin $\mathbf{5}$ were not reflected in the experimental results because the recorded spectra did not show significant differences between mono- and disubstituted compounds. This discrepancy might be related to the poorly estimated interaction between the two substituents with the B3LYP pseudopotential. A direct comparison between the experimental and calculated spectra is shown in Figure $3 \mathrm{~b}$, where the oscillator strength of the calculated first six excitation channels and the experimental absorbance spectrum of the $4 \mathrm{~d}$ sample are superimposed.

Correlations between the coumarin substitution and the emission properties are also detectable in Figure $4 a$, in which the recorded spectra show a large emission shift of about 70 $\mathrm{nm}$ between $\mathbf{4 a}$ and $4 \mathrm{c}$. On the other hand, experimental and calculated emission peak data for compounds $\mathbf{5 b}, \mathbf{4 c}, \mathbf{4 e}$, and 4f are almost overlapping. While in the calculated transitions, a shift of more than $25 \mathrm{~nm}$ was obtained, leading to the larger predicted redshift for the derivative 4c. Again, disubstituted coumarins $\mathbf{5} \mathbf{a}$ and $\mathbf{5 b}$ show an emission redshift of about 15 and $20 \mathrm{~nm}$, respectively (Figure 4a), which is about half the predicted shift (see Supporting Information).

Nevertheless, a series of solvatochromic studies on coumarins $\mathbf{4 a - 4 c}, \mathbf{4 e}$, and $\mathbf{4 f}$ were carried out using $n$-hexane, toluene, diethyl ether, and chloroform. These investigations highlighted large emission shifts $(>60 \mathrm{~nm})$ for various coumarin dyes. As an example, in Figure $4 \mathrm{~b}$, we show the solvatochromism of the dye $4 \mathbf{e}$, while the maximum peak values for the adducts $\mathbf{4 a - 4 c}$ and $\mathbf{4 e - 4 f}$ are listed in Table 1 (further solvatochromism investigations have been reported in the Supporting Information).

Coumarins 4 and 5 were excited at $350 \mathrm{~nm}$ in order to record their decay time. All the compounds showed a single exponential decay with lifetimes ranging from subnanoseconds as in the cases of compounds $\mathbf{4 a}$ and $\mathbf{5 a}$ to 9 and 13 ns for $\mathbf{4 f}$ and $4 \mathbf{e}$, respectively (Figure 5). These investigations also highlighted that by varying the acceptor group, we could observe a lifetime increase ( $\left.\mathrm{SO}_{2} \mathrm{Me}>\mathrm{CN}>\mathrm{COOEt}\right)$.

Besides, the larger Stoke shifts and quantum yield have been observed for the compounds $\mathbf{4 e}$ and $\mathbf{4 f}$. Table 2 summarizes
Table 1. Emission Values of Coumarins $4 a-4 c, 4 e$, and $4 f$ Measured in a Selected Panel of Solvents ${ }^{a}$

\begin{tabular}{|c|c|c|c|c|}
\hline coumarin & $\begin{array}{l}\lambda_{\mathrm{em}}-n-\mathrm{Hex} \\
\quad(\mathrm{nm})\end{array}$ & $\begin{array}{c}\lambda_{\text {em }}-\mathrm{Tol} \\
(\mathrm{nm})\end{array}$ & $\begin{array}{c}\lambda_{\mathrm{em}}-\mathrm{Et}_{2} \mathrm{O} \\
(\mathrm{nm})\end{array}$ & $\begin{array}{c}\lambda_{\mathrm{em}}-\mathrm{CHCl}_{3} \\
(\mathrm{~nm})\end{array}$ \\
\hline $4 a$ & 441 & 449 & 450 & 457 \\
\hline $4 b$ & 454 & 470 & 475 & 498 \\
\hline $4 c$ & 455 & 477 & 485 & 515 \\
\hline $4 e$ & 454 & 480 & 493 & 512 \\
\hline $4 f$ & 452 & 476 & 484 & 510 \\
\hline
\end{tabular}

the spectral features for both coumarins $\mathbf{4 a - 4 f}$ and $\mathbf{5 a}-\mathbf{5 b}$ in chloroform solutions.

The most promising coumarins $4 \mathbf{b}, \mathbf{4 e}$, and $4 \mathbf{f}(10 \mu \mathrm{M}$ in chloroform) were submitted to a series of additional investigations. Fluorescence emission experiments were carried out in the presence of protic acids in order to evaluate the acidochromism properties of these compounds (Figure 6). In this investigation, trifluoroacetyl (TFA) titrations caused a general variation (decrease) in the fluorescence maximum and sensible redshift from 512 to $536 \mathrm{~nm}$ for the coumarin $4 \mathrm{e}$ (Figure 6a), from 510 to $533 \mathrm{~nm}$ for $\mathbf{4 f}$ (Figure 6b), and from 496 to 508 for $\mathbf{4 b}$ (Figure S5, Supporting Information). These emission redshifts should be mainly due to the protonation of the nitrile group of $4 \mathbf{e}$ and the ester functions for the adducts 4b and 4f. Furthermore, for all three dyes, a decrease in luminescence was observed, revealing acidochromic activity (fluorescence turn-off). Then, in separated experiments, compounds $\mathbf{4 c}, \mathbf{4 e}$, and $\mathbf{4 f}$ were submitted to a series of titrations with $\mathrm{C}$ - or $\mathrm{N}$-protected amino acids or with solutions of selected metal salts $\left(\mathrm{Co}^{2+}, \mathrm{Sn}^{2+}, \mathrm{Ca}^{2+}, \mathrm{Cu}^{2+}, \mathrm{Al}^{3+}, \mathrm{Gd}^{3+}\right.$, and $\mathrm{Fe}^{3+}$ ) aiming to identify any selective interaction with organic or inorganic entities that would indicate potential sensor properties for these compounds. However, experiments conducted with ammino acids were ineffective (see Supporting Information).

Coumarins $4 \mathrm{e}$ and $\mathbf{4 f}$ showed sensible variation in their emission spectra when $\mathrm{Al}^{3+}$ and $\mathrm{Fe}^{3+}$ (albeit less markedly $\mathrm{Cu}^{2+}$ ) salts were added to their solutions as illustrated in Figure 7a,b (titration methods and further emission/ absorption spectra related to these investigations are reported in the Supporting Information). Notably, in the presence of $\mathrm{Fe}^{3+}$, the fluorescence spectra of adducts $\mathbf{4 e}$ and $\mathbf{4 f}$ exhibited an appreciable fluorescence turn-off response (Figure $7 \mathrm{a}$ ). On the other hand, the addition of $\mathrm{Al}^{3+}$ salts to $4 \mathrm{e}$ and $\mathbf{4 f}$ solutions caused fluorescence enhancement and a slight blue shift, as shown in Figure $7 \mathrm{~b}$.

Finally, the coumarins $4 \mathrm{c}\left(\lambda_{\mathrm{abs}}=303,372\right), 4 \mathrm{e}\left(\lambda_{\mathrm{abs}}=283\right.$, $380)$, and $4 \mathrm{f}\left(\lambda_{\mathrm{abs}}=288,368\right)$ were valued as potential biomarkers for bioimaging applications. For this purpose, cytotoxicity in cell-based assay was evaluated by using Nthy-ori 3-1 cells [Simian Virus 40 (SV40)-immortalized normal human thyrocytes]. Cultured cells were treated with different concentrations $(10-100 \mu \mathrm{M})$ of $\mathbf{4 c}, \mathbf{4 e}$, and $4 \mathbf{f}$. Then, cell viability was determined after $24 \mathrm{~h}$ at $37{ }^{\circ} \mathrm{C}$ by the MTT method. ${ }^{23}$ As shown in Figure 8, both coumarins have proved to be noncytotoxic against cell monolayers $($ CC50 $=>100$ $\mu \mathrm{M})$. In parallel, the Nthy-ori 3-1 cells were incubated with $4 c$, $4 \mathrm{e}$, and $4 \mathrm{f}(1.0 \mu \mathrm{M})$ for bioimaging studies and then analyzed by an epifluorescence microscope using blue (excitation 470-495 nm; emission 510-550 nm) and orange filters (excitation $530-550 \mathrm{~nm}$; emission $575 \mathrm{~nm}$ ). As shown 


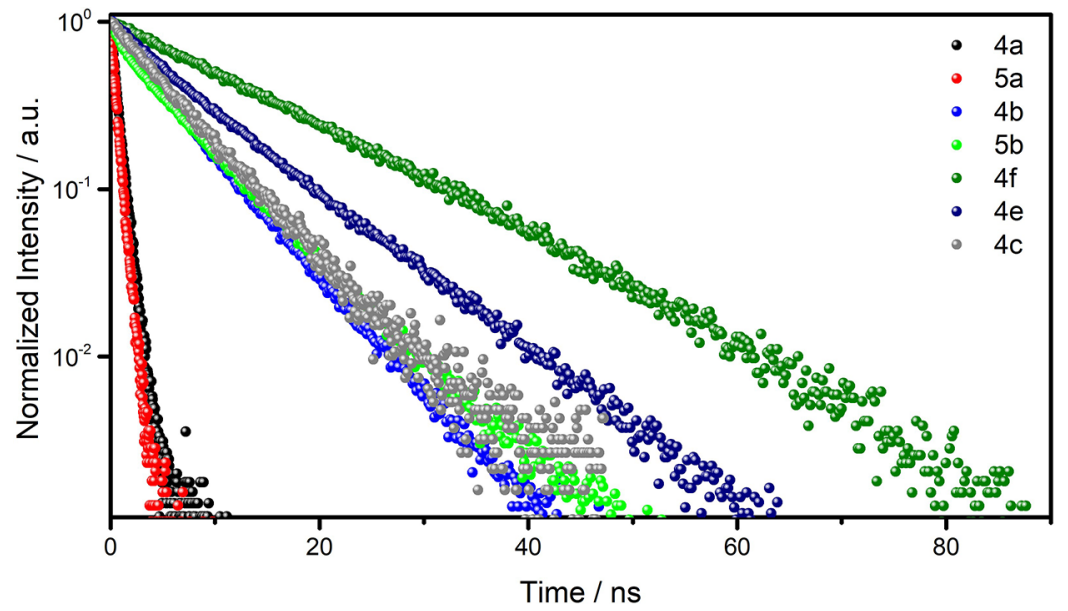

Figure 5. Decay time plot of coumarins $\mathbf{4 a - 4 c}, \mathbf{4 e - 4 f}$, and $\mathbf{5 a - 5 b}$ under excitation at $350 \mathrm{~nm}$.

Table 2. Photophysical Properties of Coumarins ${ }^{a}$

\begin{tabular}{clccc} 
coumarin & \multicolumn{1}{c}{$\lambda_{\text {abs }}(\mathrm{nm})$} & $\lambda_{\mathrm{PL}}(\mathrm{nm})$ & $\Phi^{b}$ & $\tau(\mathrm{ns})$ \\
$\mathbf{4 a}$ & $258,295,357$ & 456 & 0.05 & 0.7 \\
$\mathbf{5 a}$ & $252,309,365$ & 465 & 0.03 & 0.6 \\
4b & 274,370 & 500 & 0.15 & 6.0 \\
$\mathbf{5 b}$ & 280 & 520 & 0.12 & 5.7 \\
$\mathbf{4 c}$ & 303,372 & 515 & 0.13 & 6.0 \\
$\mathbf{4 e}$ & 283,380 & 512 & 0.45 & 9.3 \\
$\mathbf{4 f}$ & 288,368 & 510 & 0.69 & 13.0
\end{tabular}

${ }^{a}$ Fluorescence characteristics of coumarins $4 \mathbf{a}-4 \mathbf{c}, 4 \mathbf{e}-\mathbf{4 f}$, and $\mathbf{5 a}-\mathbf{5 b}$ (chloroform solution). ${ }^{b} \Phi$ values were calculated using rhodamine $6 \mathrm{G}$ as ref 22 .

in Figure 9, no fluorescence was detected in the external buffer or the nucleus, whereas collected images showed that all the coumarin dyes are emissive in the cytoplasmic compartments.

Furthermore, the intracellular environment does not affect the fluorescence properties of these compounds. These pieces of evidence prompted us to deduce that coumarins tend to interact at the cytoplasmic lipophilic substructures, helped by their poor solubility in water. However, to confirm this hypothesis, high-resolution confocal microscopy studies are ongoing in our laboratories.

\section{CONCLUSIONS}

The synthesis of new push-pull coumarins was successfully performed with a two-step strategy in good to satisfactory yields. Photophysical characterization allowed us to identify a series of derivatives endowed by good quantum fluorescence efficiencies, also characterized by solvatochromic and acidochromic properties. Compounds $\mathbf{4 e}$ and $\mathbf{4 f}$ showed certain selectivity for $\mathrm{Fe}^{3+}$ salts, causing fluorescence turn-off, while the addition of $\mathrm{Al}^{3+}$ enhanced their fluorescence. Nevertheless, in vitro bioassays highlighted the low toxicity of coumarins $4 c$, $4 \mathbf{e}$, and $4 \mathrm{f}$ that were thus investigated as potential candidates for bioimaging applications. To this end, further studies are currently ongoing in our laboratory, aimed at identifying any
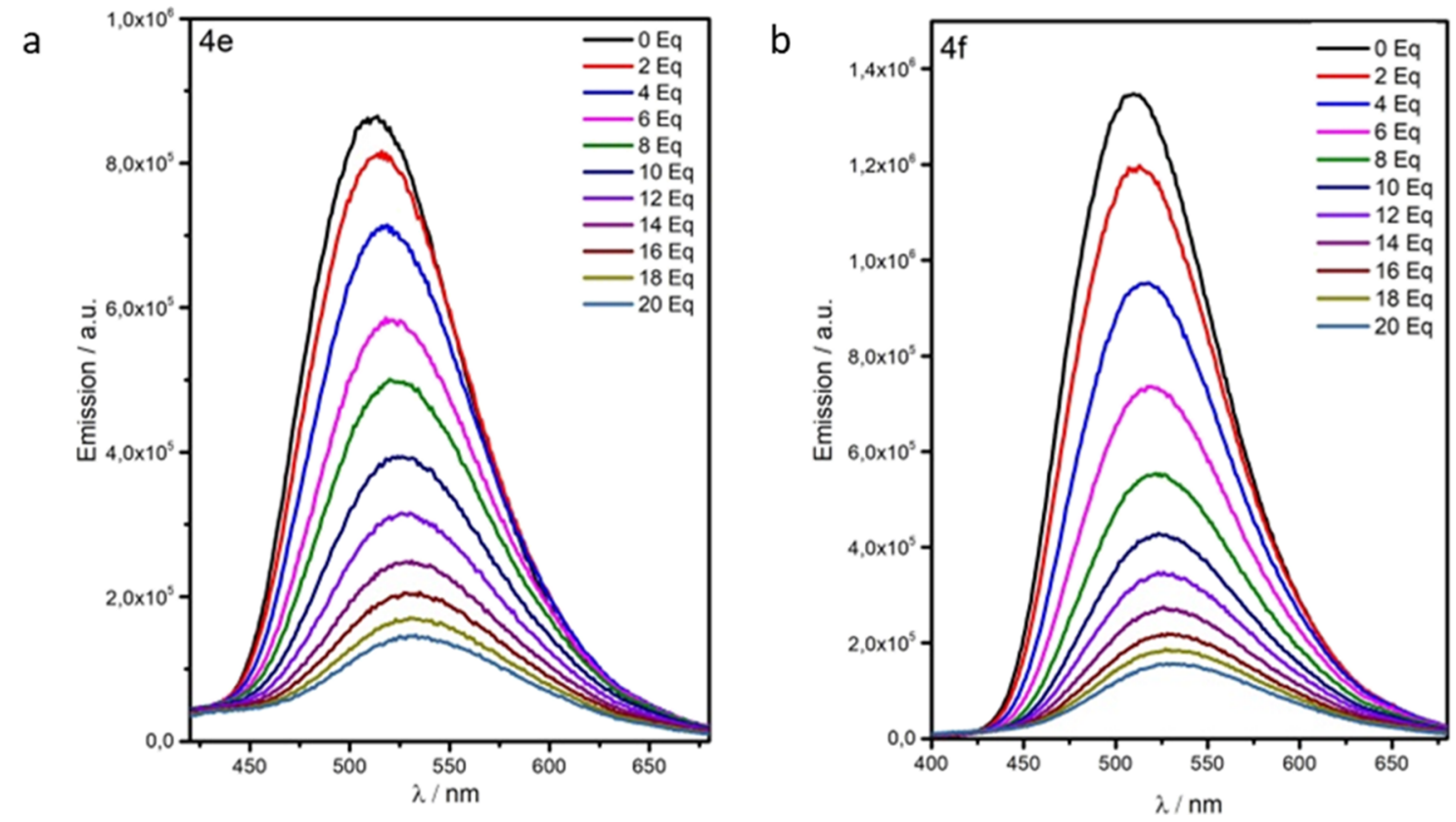

Figure 6. Changes in the emission spectra of (a) $4 \mathrm{e}$ and (b) $4 \mathrm{f}(10 \mu \mathrm{M})$ with the incremental addition of TFA in chloroform $\left(\lambda_{\mathrm{ex}}=350 \mathrm{~nm}\right)$. 

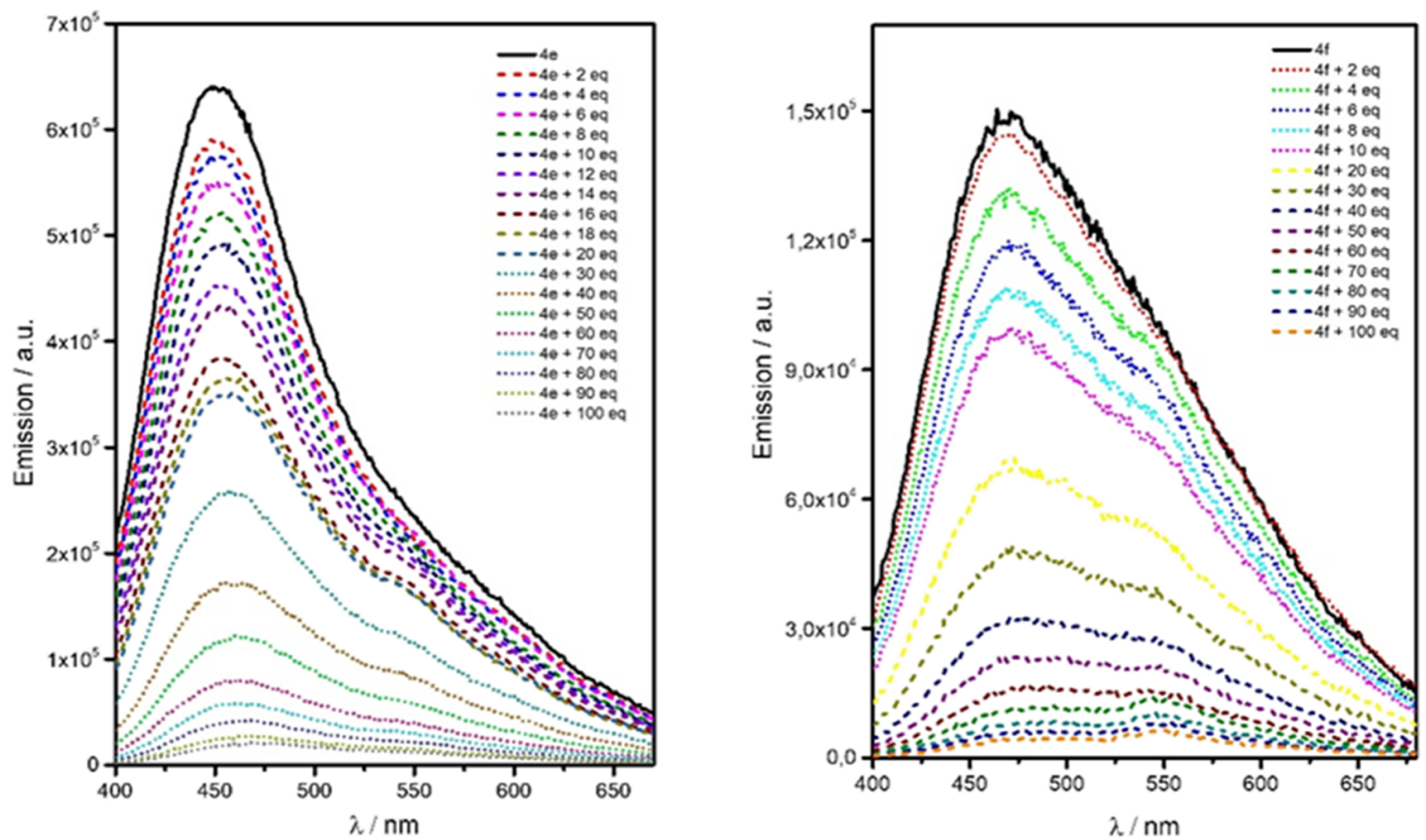

b
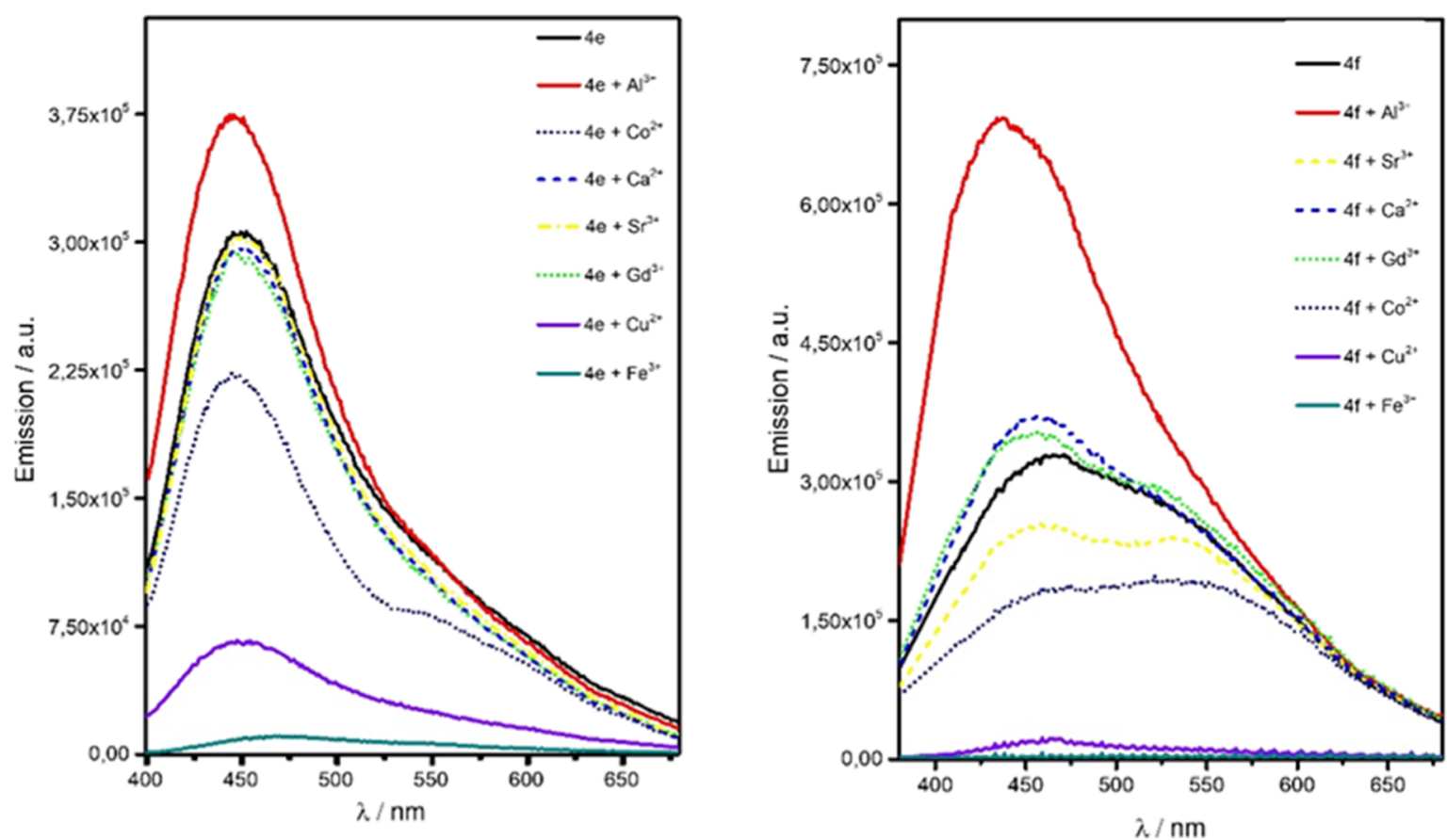

Figure 7. (a) Fluorescence emission spectra of coumarins $4 \mathbf{e}$ and $4 \mathrm{f}(10 \mu \mathrm{M})$ titrated with $\mathrm{Fe}^{3+}$ salts $(0-100$ equiv) in methanol. (b) Fluorescence spectra of coumarins $4 \mathrm{e}$ and $4 \mathrm{f}(10 \mu \mathrm{M})$ in the presence of different metal ions (100 equiv) in methanol.

selectivity of these compounds toward specific cytoplasmic subunits.

\section{METHODS}

All the reagents were purchased from Merk or TCI and used without further purification.

UV-vis absorbance spectra were carried out with a Varian Cary 60 spectrophotometer $(200-600 \mathrm{~nm})$. Emission spectra were collected ( $90^{\circ}$ geometry) with a HORIBA Jobin Yvon FluoroMax 3.0 spectrofluorometer (300-600 nm range). In both cases, a quartz cuvette (10 $\mathrm{mm}$ optical path) was used. Time-resolved measurements were carried out by exciting the samples in the UV range with $200 \mathrm{fs}$ long pulsed laser light delivered by an optical parametric amplifier (Light Conversion TOPAS-C) pumped by a regenerative $\mathrm{Ti}$ /sapphire amplifier (Coherent Libra-HE, repetition frequency $1 \mathrm{kHz}$ ). The PL signals were recorded by a streak camera (Hamamatsu C10910) equipped with a grating spectrometer (Princeton Instruments Acton SpectraPro SP-2300). The emission signals were gathered in the front face mode in order to avoid inner filter effects. ${ }^{1} \mathrm{H}$ NMR spectra were recorded on a $500 \mathrm{MHz}$ Varian spectrometer at $25{ }^{\circ} \mathrm{C}$ using $\mathrm{CDCl}_{3}$ (ref. $7.26 \mathrm{ppm}$ ) as the solvent. ${ }^{13} \mathrm{C}$ NMR spectra were recorded at $126 \mathrm{MHz}$ (ref. $\mathrm{CDCl}_{3} 77.16 \mathrm{ppm}$ ) using $\mathrm{CDCl}_{3}$ as the solvent. The chemical 


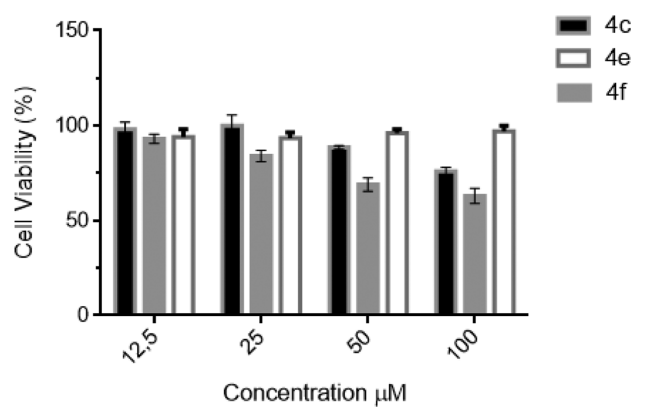

Figure 8. Viability of the Nthy-ori 3-1 cell line in the presence of $4 \mathrm{c}$ (black), $4 \mathrm{e}$ (white), and $\mathbf{4 f}$ (gray). The cells were treated at different concentrations, and cytotoxicity was determined using the MTT assay by monitoring formazan absorbance at $570 \mathrm{~nm}$. Data represent mean values $( \pm S D)$ for three independent determinations. shifts $(\delta)$ are given in ppm. The coupling constants $(J)$ are reported in Hz. Low mass spectra analysis was recorded using Agilent-HP GC-MS (E.I. $70 \mathrm{eV}$ ). High-resolution mass spectra (HRMS) of compounds 3, 4, and 5 were obtained using a high-resolution mass spectrometer in fast atom bombardment ionization mode acquired using Bruker micrOTOF-Q II or/and Agilent Q-TOF 6520. The melting points were determined with Büchi M-560 $\left({ }^{\circ} \mathrm{C}\right)$. Analytical thin-layer chromatography was performed using $0.25 \mathrm{~mm}$ Aldrich silica gel $60-\mathrm{F}$ plates. Flash chromatography was performed using Merck 70-200 mesh silica gel. Yields refer to chromatography and/or spectroscopically pure materials. Acetone, acetonitrile, and ethyl acetate were used as received (HPLC grade $>99 \%$ ) or distilled with the appropriate procedure. THF and toluene were distilled from sodium/benzophenone ketyl. All the simulations were performed with the Gaussian 16 package $^{18}$

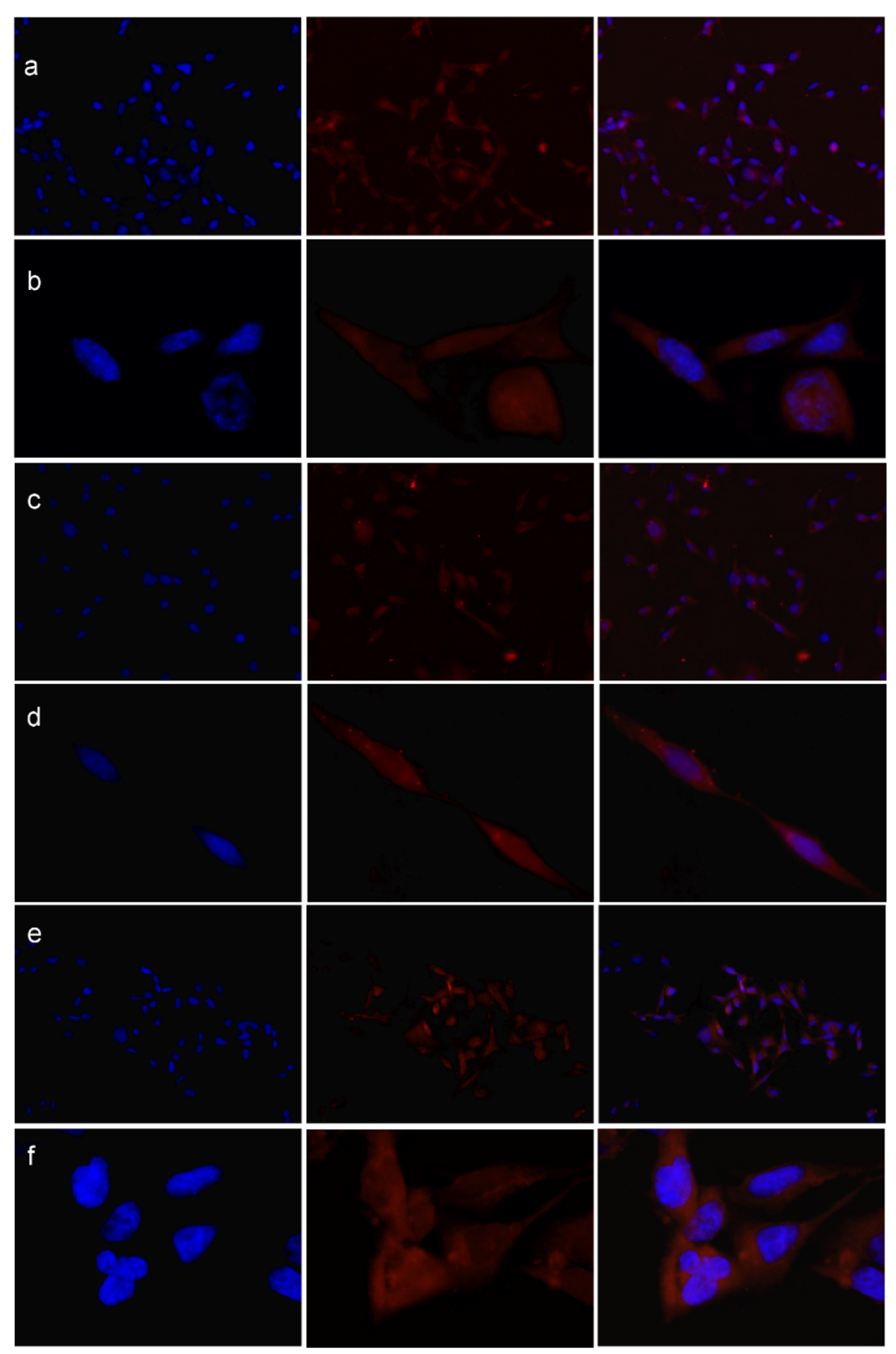

Figure 9. Bioimaging of Nthy-ori 3-1 cells treated with $4 \mathbf{c}$, $4 \mathbf{e}$, and $4 \mathbf{f}$ coumarins $(1 \mu \mathrm{M})$. (a) $20 \times$ and (b) $100 \times$ fluorescent images of Nthy-ori $3-$ 1 cells treated with $4 \mathrm{c}$ coumarin; (c) $20 \times$ and (d) $100 \times$ fluorescent images of Nthy-ori $3-1$ cells treated with $4 \mathrm{e}$ coumarin; and (e) $20 \times$ and (f) $100 \times$ fluorescent images of Nthy-ori 3-1 cells treated with $4 \mathrm{f}$ coumarin. Blue: cell nuclei. Orange: coumarins. 
to optimize the structures down to the self-consistent field energy and to calculate their optical properties. Ground and excited states were simulated within DFT and TDDFT frameworks, respectively, by exploiting the B3LYP hybrid functional with the $6-31 \mathrm{G}(\mathrm{d}, \mathrm{p})$ basis set as already reported for similar compounds. ${ }^{19}$ The simulations were accomplished under vacuum and with a model solvent, chloroform. In the latter cases, solvation effects arising from the interaction of coumarin derivatives with chloroform were treated with the self-consistent reaction field model by simulating the dielectric solvent through the polarizable continuum model calculation with-in the integral equation formalism. ${ }^{20}$

The Nthy-ori 3-1 cell line [Simian Virus 40 (SV40)immortalized normal human thyrocytes] was purchased from the Health Protection Agency Culture Collections (Health Protection Agency Culture Collections; 2011 http://www.hpa. org.uk, last accessed on 20 May 2021).

The absence of mycoplasma contamination was checked periodically by the Hoechst staining method. The cells were grown as monolayers in DMEM/Ham's F-12 (DMEM/F12) supplemented with 10\% FBS (Life Technologies, Milan, Italy), $100 \mathrm{UI} / \mathrm{mL}$ penicillin, and $100 \mu \mathrm{g} / \mathrm{mL}$ streptomycin (SigmaAldrich, Milan, Italy), at $37{ }^{\circ} \mathrm{C}$ in a humidified $5 \% \mathrm{CO}_{2}$ atmosphere.

To evaluate the cytotoxic effect of $\mathbf{4 c}, \mathbf{4 e}$, and $\mathbf{4 f}$, MTT assay was performed. Briefly, the cells were seeded at a density of 7.5 $\times 10^{3}$ cells in a 96-well plate and incubated for $24 \mathrm{~h}$. Then, the compounds were added at different concentrations (10-100 $\mu \mathrm{M})$, and the cells were further incubated for $24 \mathrm{~h}$. After incubation, $50 \mu \mathrm{L}$ of MTT reagent ( $1 \mathrm{mg} / \mathrm{mL}$ in DMEM/F12) was added, and then, the cells were incubated for an additional $4 \mathrm{~h}$. The resulting formazan crystals were dissolved in $100 \mu \mathrm{L}$ of DMSO. The absorbances were measured at $570 \mathrm{~nm}$ using a Tecan microplate reader (Infinite 200, Tecan, Salzburg, Austria). The extent of cell growth/viability at each coumarin concentration tested was expressed as a percentage of untreated controls. Concentrations resulting in 50\% inhibition (CC50) were determined by linear regression analysis.

For cellular bioimaging assay, the cells were grown on coverslips. After $24 \mathrm{~h}$ with the designed compound solution (1 $\mu \mathrm{M})$, the cells were washed three times in PBS $1 \times(\mathrm{pH} 7.4)$ and then fixed in $3.7 \%$ formaldehyde for $30 \mathrm{~min}$. The slides were then washed with PBS $1 \times$ and mounted in antifading solution with $0.15 \mu \mathrm{g} / \mathrm{mL}$ DAPI as a counterstain. The samples were analyzed using a digital image analysis system based on an epifluorescence Olympus BX41 microscope using blue (excitation 470-495 nm; emission 510-550 nm) and orange filters (excitation $530-550 \mathrm{~nm}$; emission $575 \mathrm{~nm}$ ) and a charge-coupled device camera (Cohu, San Diego, CA) interfaced with the CytoVysion System (Applied Imaging).

\section{ASSOCIATED CONTENT}

\section{SI Supporting Information}

The Supporting Information is available free of charge at https://pubs.acs.org/doi/10.1021/acsomega.1c04810.

${ }^{1} \mathrm{H}$ and ${ }^{13} \mathrm{C}$ NMR spectra and photophysical data (PDF)

\section{AUTHOR INFORMATION}

\section{Corresponding Authors}

Carlo Maria Carbonaro - Department of Physics, University of Cagliari, 09042 Cagliari, Italy; 이이.org/0000-00016353-6409; Email: cm.carbonaro@dsf.unica.it
Francesco Secci - Department of Chemical and Geological Sciences, University of Cagliari, 09042 Cagliari, Italy; ○ orcid.org/0000-0003-0443-2890; Email: fsecci@unica.it

\section{Authors}

Andrea Cocco - Department of Chemical and Geological Sciences, University of Cagliari, 09042 Cagliari, Italy

Paola Caria - Department of Biomedical Sciences, University of Cagliari, 09042 Cagliari, Italy

Giuseppina Sanna - Department of Biomedical Sciences, University of Cagliari, 09042 Cagliari, Italy

Luigi Stagi - Department of Chemistry and Pharmacy, Laboratory of Materials Science and Nanotechnology, CRINSTM, University of Sassari, 07100 Sassari, Italy; (1) orcid.org/0000-0002-7238-8425

Enzo Cadoni - Department of Chemical and Geological Sciences, University of Cagliari, 09042 Cagliari, Italy

Riccardo Corpino - Department of Physics, University of Cagliari, 09042 Cagliari, Italy; o orcid.org/0000-00034480-7175

Pier Carlo Ricci - Department of Physics, University of Cagliari, 09042 Cagliari, Italy; 이이.org/0000-00016191-4613

Complete contact information is available at:

https://pubs.acs.org/10.1021/acsomega.1c04810

\section{Author Contributions}

The manuscript was written through the contributions of all authors. All authors have given approval to the final version of the manuscript.

\section{Notes}

The authors declare no competing financial interest.

\section{ACKNOWLEDGMENTS}

We acknowledge Sardinia Regional Government (RAS) for the financial support of A.C. Ph.D scholarship Programma Operativo Nazionale FSE-FESR Ricerca e Innovazione 2014-2020 (PON RI 2014-2020), Asse I "Capitale Umano," Azione I.1 "Dottorati Innovativi con caratterizzazione industriale," and (FIR 2020-2010). We also acknowledge the financial support from the "Fondazione di Sardegna" within the project L.R 7. CUP F74I19000930007 "NG-Light: a new generation of phosphors." The CeSAR (Centro Servizi d'Ateneo per la Ricerca) of the University of Cagliari, Italy, is also acknowledged for the time-resolved photoluminescence experiments.

\section{REFERENCES}

(1) Kivala, M.; Diederich, F. Acetylene-Derived Strong Organic Acceptors for Planar and Nonplanar Push-Pull Chromophores. Acc. Chem. Res. 2009, 42, 235-248.

(2) He, C.; He, Q.; Yang, X.; Wu, G.; Yang, C.; Bai, F.; Shuai, Z.; Wang, L.; Li, Y. Synthesis and Photovoltaic Properties of a SolutionProcessable Organic Molecule Containing Triphenylamine and DCM Moieties. J. Phys. Chem. C 2007, 111, 8661-8666.

(3) Starčević, S.; Brožič, P.; Turk, S.; Cesar, J.; LanišnikRižner, T.; Gobec, S. Synthesis andBiological Evaluation of (6- and 7-Phenyl) Coumarin Derivatives as Selective Nonsteroidal Inhibitors of $17 \beta$ Hydroxysteroid Dehydrogenase Type 1. J. Med. Chem. 2011, 54, 248-261.

(4) Gudeika, D.; Michaleviciute, A.; Grazulevicius, J. V.; Lygaitis, R.; Grigalevicius, S.; Jankauskas, V.; Miasojedovas, A.; Jursenas, S.; Sini, G. Structure Properties Relationship of Donor-Acceptor Derivatives 
of Triphenylamine and 1,8-Naphthalimide. J. Phys. Chem. C 2012, 116, 14811-14819.

(5) Jagtap, A. R.; Satam, V. S.; Rajule, R. N.; Kanetkar, V. R. The Synthesis and Characterization of Novel Coumarin Dyes Derived from 1,4-Diethyl-1,2,3,4-Tetrahydro-7-Hydroxyquinoxalin-6-Carboxaldehyde. Dyes Pigm. 2009, 82, 84-89.

(6) Galievsky, V. A.; Druzhinin, S. I.; Demeter, A.; Mayer, P.; Kovalenko, S. A.; Senyushkina, T. A.; Zachariasse, K. A. Ultrafast Intramolecular Charge Transfer with $\mathrm{N}$-(4-Cyanophenyl)Carbazole. Evidence for a LE Precursor and Dual LE + ICT Fluorescence. J. Phys. Chem. A 2010, 114, 12622-12638.

(7) Prathap, K. N. C.; Lokanath, N. K. Synthesis, characterization, crystal structure and quantum chemical investigations of three novel coumarin-benzenesulfonohydrazide derivatives. J. Mol. Struct. 2018, $1158,26-38$.

(8) Traven, V. F.; Cheptsov, D. A.; Solovjova, N. P.; Chibisova, T. A.; Voronov, I. I.; Dolotov, S. M.; Ivanov, I. V. Photoinduced Formation of the Laser Dye Coumarin 6 from Its Dihydro Derivatives. Dyes Pigm. 2017, 146, 159-168.

(9) Zhou, X.; Blochwitz-Nimoth, J.; Pfeiffer, M.; Maennig, B.; Drechsel, J.; Werner, A.; Leo, K. Inverted Transparent Multi-Layered Vacuum Deposited Organic Light-Emitting Diodes with Electrically Doped Carrier Transport Layers and Coumarin Doped Emissive Layer. Synth. Met. 2003, 138, 193-196.

(10) Beyer, B.; Griese, D.; Schirrmann, C.; Pfeifer, R.; Kahmann, S.; Hild, O. R.; Leo, K. Small Molecule Bulk Heterojunction Organic Solar Cells with Coumarin-6 as Donor Material. Thin Solid Films 2013, 536, 206-210.

(11) Signore, G.; Nifosì, R.; Albertazzi, L.; Storti, B.; Bizzarri, R. Polarity-Sensitive Coumarins Tailored to Live Cell Imaging. J. Am. Chem. Soc. 2010, 132, 1276-1288.

(12) Bayrakçeken, F.; Yaman, A.; Hayval, M. Photophysical and Photochemical Study of Laser-Dye Coumarin-481 and Its Photoproduct in Solution. Spectrochim. Acta, Part A 2005, 61, 983-987.

(13) Yuan, S.; Zhang, Y.; Lu, R.; Yu, A. Photoinduced Electron Transfer between Coumarin Dyes and N,N-Dimethylaniline in Imidazolium Based Room Temperature Ionic Liquids: Effect of the Cation's Alkyl Chain Length on the Bimolecular Photoinduced Electron Transfer Process. J. Photochem. Photobiol., A 2013, 260, 3949.

(14) (a) Hori, Y.; Norinobu, T.; Sato, M.; Arita, K.; Shirakawa, M.; Kikuchi, K. Development of Fluorogenic Probes for Quick No-Wash Live-Cell Imaging of Intracellular Proteins. J. Am. Chem. Soc. 2013, 135, 12360-12365. (b) Kim, D.; Baik, S. H.; Kang, S.; Cho, S. W.; Bae, J.; Cha, M.-Y.; Sailor, M. J.; Mook-Jung, I.; Ahn, K. H. Close Correlation of Monoamine Oxidase Activity with Progress of Alzheimer's Disease in Mice, Observed by in Vivo Two-Photon Imaging. ACS Cent. Sci. 2016, 2, 967-975. (c) Liu, X.; Cole, J. M.; Waddell, P. G.; Lin, T.-C.; Radia, J.; Zeidler, A. Molecular Origins of Optoelectronic Properties in Coumarin Dyes: Toward Designer Solar Cell and Laser Applications. J. Phys. Chem. A 2012, 116, 727-737.

(15) Azuma, K.; Suzuki, S.; Uchiyama, S.; Kajiro, T.; Santa, T.; Imai, K. A Study of the Relationship between the Chemical Structures and the Fluorescence Quantum Yields of Coumarins, Quinoxalinones and Benzoxazinones for the Development of Sensitive Fluorescent Derivatization Reagents. Photochem. Photobiol. Sci. 2003, 2, 443.

(16) Tasior, M.; Kim, D.; Singha, S.; Krzeszewski, M.; Ahn, K. H.; Gryko, D. T. $\pi$-Expanded Coumarins: Synthesis, Optical Properties and Applications. J. Mater. Chem. C 2015, 3, 1421-1446.

(17) Kim, D.; Xuan, Q. P.; Moon, H.; Jun, Y. W.; Ahn, K. H. Synthesis of Benzocoumarins and Characterization of Their Photophysical Properties. Asian J. Org. Chem. 2014, 3, 1089-1096.

(18) Frisch, M. J.; Trucks, G. W.; Schlegel, H. B.; Scuseria, G. E.; Robb, M. A.; Cheeseman, J. R.; Scalmani, G.; Barone, V.; Petersson, G. A.; Nakatsuji, H. et al. Gaussian 16, Revision C. 01; Gaussian Inc: Wallingford, CT, 2016.

(19) Cappai, A.; Melis, C.; Stagi, L.; Ricci, P. C.; Mocci, F.; Carbonaro, C. M. Insight into the Molecular Model in Carbon Dots through Experimental and Theoretical Analysis of Citrazinic Acid in Aqueous Solution. J. Phys. Chem. C 2021, 125, 4836-4845.

(20) Cancès, E.; Mennucci, B.; Tomasi, J. "A new integral equation formalism for the polarizable continuum model: Theoretical background and applications to isotropic and anisotropic dielectrics". J. Chem. Phys. 1997, 107, 3032-3041.

(21) (a) Ghanei-Nasab, S.; Khoobi, M.; Hadizadeh, F.; Marjani, A.; Moradi, A.; Nadri, H.; Emami, S.; Foroumadi, A.; Shafiee, A. Synthesis and anticholinesterase activity of coumarin-3-carboxamides bearing tryptamine moiety. Eur. J. Med. Chem. 2016, 121, 40-46. (b) Costa, M.; Areias, F.; Abrunhosa, L.; Venâncio, A.; Proença, F. The Condensation of Salicylaldehydes and Malononitrile Revisited:Synthesis of New Dimeric Chromene Derivatives. J. Org. Chem. 2008, 73, 1954-1962. (c) He, X.; Shang, Y.; Zhou, Y.; Yu, Z.; Han, G.; Jin, W.; Chen, J. Synthesis of coumarin-3-carboxylic esters via $\mathrm{FeCl}_{3}$ catalyzed multicomponent reaction of salicylaldehydes, Meldrum's acid and alcohols. Tetrahedron 2015, 71, 863-868. (d) Bonsignore, L.; Cottiglia, F.; Maccioni, A. M.; Secci, D.; Lavagna, S. M. Synthesis of coumarin-3-O-acylisoureas by dicyclohexylcarbodiimide. J. Heterocycl. Chem. 1995, 32, 573-577. (e) Ghanei-Nasab, S.; Khoobi, M.; Hadizadeh, F.; Marjani, A.; Moradi, A.; Nadri, H.; Emami, S.; Foroumadi, A.; Shafiee, A. Synthesis and anticholinesterase activity of coumarin-3-carboxamides bearing tryptamine moiety. Eur. J. Med. Chem. 2016, 121, 40-46.

(22) Kubin, R. F.; Fletcher, A. N. Fluorescence Quantum Yields of Some Rhodamine Dyes. J. Lumin. 1982, 27, 455-462.

(23) Tronci, L.; Serreli, G.; Piras, C.; Frau, D. V.; Dettori, T.; Deiana, M.; Murgia, F.; Santoru, M. L.; Spada, M.; Leoni, V. P.; Griffin, J. L.; Vanni, R.; Atzori, L.; Caria, P. Vitamin C Cytotoxicity and Its Effects in Redox Homeostasis and Energetic Metabolism in Papillary Thyroid Carcinoma Cell Lines. Antioxidants 2021, 10, 809823. 